Article

\title{
Towards a Revised Framework for Participatory Planning in the Context of Risk
}

\author{
Paola Rizzi ${ }^{1, *(1)}$ and Anna Porębska ${ }^{2}$ (I) \\ 1 Department of Architecture, Design and Urban Planning, University of Sassari, 07100 Sassari, Italy \\ 2 Faculty of Architecture, Cracow University of Technology, 31-155 Kraków, Poland; anna.porebska@pk.edu.pl \\ * Correspondence: rizzi@uniss.it
}

Received: 30 April 2020; Accepted: 7 July 2020; Published: 9 July 2020

check for updates

\begin{abstract}
Community participation is widely acknowledged to be crucial in both mitigation and reconstruction planning, as well as in community-based disaster risk reduction (CBDRR) and community-based disaster mitigation (CBDM) processes. However, despite decades of experience, an efficient framework that is acceptable for all actors and suitable for all different phases of the process-ranging from planning to post-disaster recovery-is lacking. The examples presented in this paper shed light on the different dynamics of participatory design processes and compare situations in which participatory design and community planning were introduced before, during, or after a disastrous or potentially disastrous event. Others emphasize the consequences of participation not being introduced at all. Analysis of these processes allows the authors to speculate on a revised, universal model for participatory planning in vulnerable territories and in the context of risk. By emphasizing intrinsic relations of different elements of the process, particularly the responsibility that different actors are prepared —or forced—to take, this article offers insight towards a framework for post-2020 participatory planning.
\end{abstract}

Keywords: participatory design; design for risk reduction (DRR); disaster mitigation (DM); risk awareness; resilience

\section{Introduction}

\subsection{Participatory Planning for Disaster Risk Reduction}

The importance of communities' involvement in urban policies has rightfully been upheld as essential. There are a variety of terms used to emphasize this role: Inclusiveness, empowerment, enhancement, responsibility, co-responsibility, co-design, co-planning, etc., and they all explain why participatory processes are so vital in urban planning. However, there is an intrinsic risk related to their application and implementation, ranging from goals and targets, be they too big or too small, to syndromes like NIMBYism (Not in My Back Yard) or If Only Syndrome.

The reasons for participatory design being less efficient than expected lie in its own complexities, blurred margins, and inconsistent narratives. Whilst the concept of sustainability was introduced in the 1980s with the goal of acknowledging the socio-natural character of interactions within built environments, theories and methods rising from the field of social sciences had already started to infiltrate the realm of urban design and planning in the 1960s, as the paradigm of planning as visionary design was beginning to be abandoned [1]. A couple of decades later, after the technocratic period of the 1970s, when even analyses, data, and technology had become inherently political, planners began to value intelligence over knowledge, and started to negotiate instead of imposing solutions. From the radical thinkers of the 1960s, through the resilient practices of the 1980s, to the new progressive approaches resulting from the current socio-political and economic challenges, as well as from planning 
as communication (1980s), through planning as envisioning together (1990s), towards the collaborative planning theory of P. Healey (1997) [2] and the communicative planning theory of J.E. Innes (1998) [3], a new paradigm has emerged. Amongst other cornerstones, it has been based on participation and resilience [4-10]. As a consequence, the role of the experts has become maieutic rather than demiurgic, making the implementation of this paradigm even more complicated.

Up to the present, technical planners and practitioners have preferred to rely on applied science tools and techniques instead of adopting new community-based models, which remains a rather academic domain. Neither Healey nor Innes managed to coin an applicable version of their theories. Hence, participatory design remains a potential of an ideal society or, as Henry Sanoff emphasizes [11-15], "an attitude about a force for change in the creation and management of environments for people" [11].

While theorists and practitioners agree on the importance and relevance of participatory design per se, or general strategies to be applied, it is difficult to find a universal operational framework or a model adaptable to various scenarios. Participatory design in an era of participation becomes challenging $[16,17]$. In addition, "the challenge of contemporary participatory design research is that while the use of participatory practices and methods is increasingly spread across domains and general discourses of design and everyday life, the values and meaning of participation itself are losing their significance" [17].

Planning in general, and planning in vulnerable areas in particular, results in launching processes in which people who conceptualize these processes, or benefit from them, and people that these processes have an impact on are distinct groups with different socio-economic backgrounds. It is but one of the many weak links in the long chain of planning. With policy-making still being based on explicitly political processes of adversary modeling instead of politically neutral expert opinions, planning for the public, at least in theory, has been replaced by planning with the public. Unfortunately, an uninvolved public is but a crowd, and a crowd can say but "YES" or "NO" (preferably cried out loud), or "NOT IN MY BACK YARD", statements that are neither participation nor planning.

Community participation is widely acknowledged to be crucial in both mitigation and reconstruction planning [18], as well as community-based disaster risk reduction (CBDRR) and community-based disaster mitigation (CBDM) processes, which differ from 'regular' disaster risk reduction (DRR) and disaster mitigation (DM). The difference lies in the approach towards the complexity of a dwelled territory, its management, and transformation. Decades of experience in applying CBDRR and CBDM proved that technical, infrastructural, or planned solutions are not efficient without the bottom-up support that only participatory processes can guarantee. However, while the latter enforce a qualitative approach to disaster risk reduction, they, conversely, tend to be underestimated in DRR and DM projects due to a lack of quantitative factors [19]. Without neglecting the importance and validity of some technical, infrastructural, or regulatory solutions for disaster risk reduction and disaster mitigation, this paper presents participatory processes in the context of post-disaster recovery and risk preparedness. These are seen as an approach towards planning a dwelled vulnerable territory and educating people who dwell in it, rather than a way to inform or apply a solution. Hence, while emergency plans are focused on training and preparation along with efficiency of infrastructures, participatory planning in vulnerable areas is focused on the concept of continuous education, awareness, and responsibility.

\subsection{The Five Ws and One $H$}

Regardless of communication being considered a theoretical framework of participatory design, communicating — and reaching a shared point of view—is key. The very concept of we, "a word that represents a collective view, continues to be problematic in participatory design" [4]. As Rachel Luck points out, "this dialectical/dialogic paradox is unresolved when participatory design is studied as a discursive practice" [4], and it often remains unresolved as far as the application phase.

So, how can a crowd be turned into the public and the public into participants? How can individual desires be included in a common realm? How can oaks and flowers be combined in one garden? 
Participation should be the answer. However, to launch successful community planning, the rule of the five W's and one $\mathrm{H}$ needs to be applied: Knowledge of the who, what, where, when, and why is necessary to define how are we going to act [10]. These may happen on different scales and at different points on a timeline. The scale can be individual, common, local, regional, interregional, national, international, global, etc., but so can be the time: Long-term, short-term, or immediate; individual, collective, physical, or political; future, present, past, or simple. They all have to be considered in different scales at the same time.

In the standard, or quasi-ideal, model of a participatory process, top-down initiatives and stimuli-be they legal, logistic, financial, etc.-are parallel to bottom-up initiatives (structural and non-structural, obligatory and optional, etc.). These result in pilot participatory actions as well as activism that subsequently facilitate specific participatory/community planning activities aimed at a defined group, however diverse, and its environment. Finally, bottom-up feedback and proposals empower the implementation that is controlled reciprocally top-down and bottom-up. The perspective, as well as the nearly endless number of complications, obstacles, and difficulties that may interfere with every step in such a process, may be discouraging. Turning people into a community, or engaging a latent one, is definitely among the most challenging. However, as proven by the case studies below, it is an effort worth making.

If being involved is the first step towards solving a problem, awareness of being a part of the problem should be its precursor. Hence, the aim of this research has been to trace the awareness of the place and the territory within the participatory processes and to include it in a revised framework.

\section{Materials and Methods}

This article presents case studies where participatory design and community planning were introduced not just after, but also during or before a disastrous or potentially disastrous event, in comparison with others where they were not introduced at all. These are, respectively: Post-earthquake reconstruction processes held in Italy in the last 50 years, summarized in the Appendix A (Table A1), large-scale infrastructural investments modified through bottom-up activities during an already-started executive procedure in Pordenone, Italy; a Japanese prefecture preparing for the upcoming Nankai megathrust earthquake and tsunami; and the 2013 flood in Olbia, Italy. These are processes with which the authors were either directly involved or to which they contributed scientifically. It also examines the general strategies of participatory design summarized in the model presented in Figure 1 and those applied in the case studies and presented in Figures 2-6. Qualitative comparative study of the examples is presented in the Appendix A (Tables A2-A6).

The basic approach of the reference participatory model is that, depending on the scale of the problem (local, regional, interregional, national), aims are respectively delegated to corresponding levels of administration, with lower levels of administration being coordinated and supported by the upper levels, while experts in co-operation with local communities prepare a solution that is subsequently scrutinized, discussed, and eventually improved. Theoretically, the specific needs of particularly vulnerable groups are met simply by including representatives of these groups in participatory processes and/or consultations. Solutions are supposed to have a positive impact on all the elements and actors, and to improve the quality of life of all dwellers and/or users, which is too much to be expected in most cases. Hence, the erosion of the entire framework starts when subsequent phases and/or elements are eliminated and/or bypassed without paying much attention to their intrinsic relations. Participatory actions are introduced too late, or confused with activism, or the geography of the system is incomplete (with exclusively infrastructural, environmental, or demographic issues being taken into consideration). As a result, the efficiency of the process is lowered, public trust in governments and stakeholders declines, and it becomes increasingly difficult to persuade people to participate, for they do not consider their voice and engagement a causative factor. 


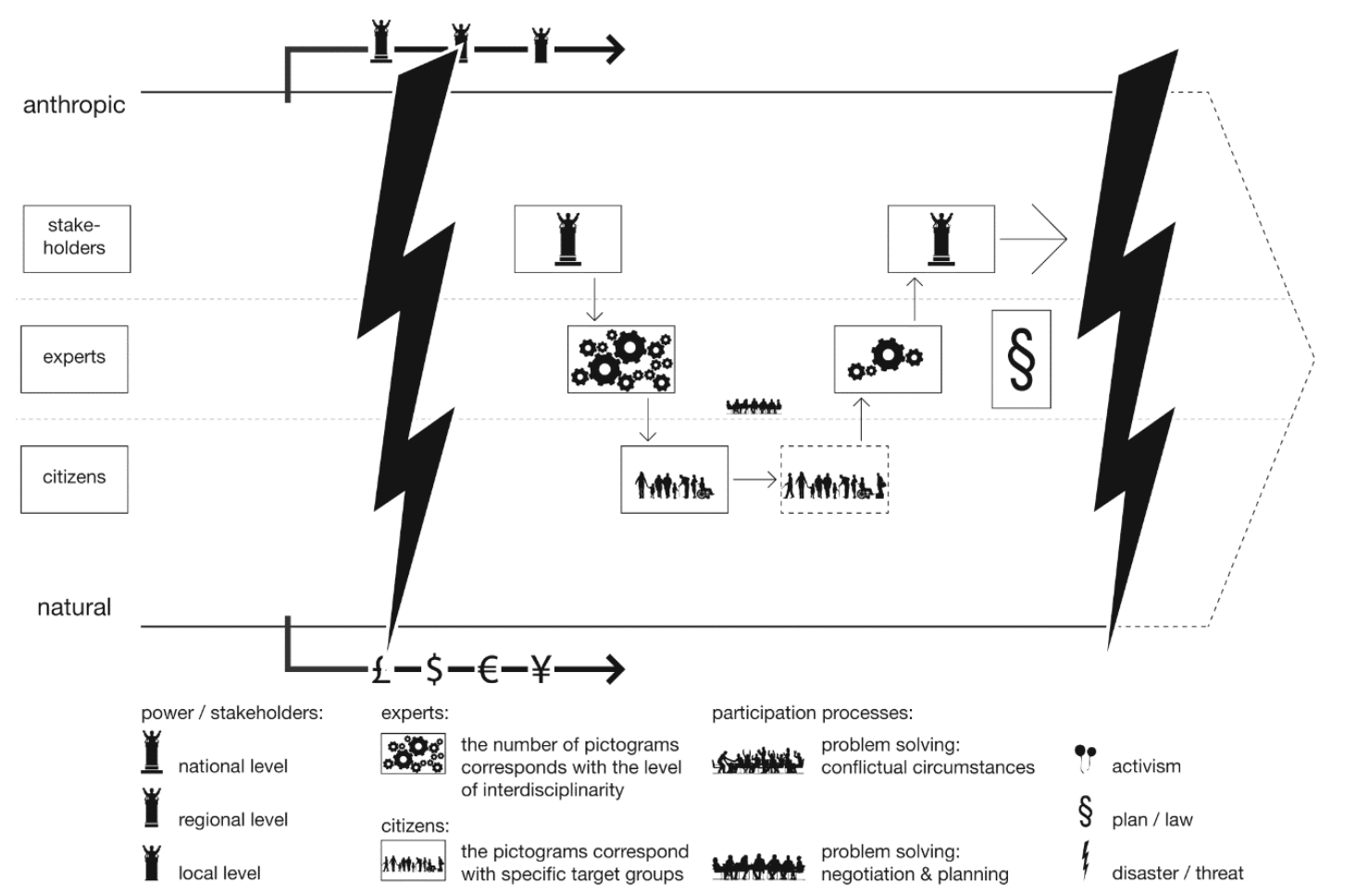

Figure 1. Reference participatory model. Top-down initiatives and stimuli (legal, logistic, financial, etc.) are parallel to bottom-up initiatives; general pilot participatory actions are parallel to activism; specific participatory planning and community planning actions are supported by activism; bottom-up feedback is parallel to participated implementation. In this participatory process that can be referred to as standard, there is a relation between different levels of governance, experts, and planners/designers (those responsible for initiating actions and providing plans and strategies) included. There is a relation between the community and the stakeholders, too; however, the character of this relation is more an institutional one, while many of the relations within the community itself are marginalized.

As a result, the authors propose a new framework-presented in Figure 7-which is based on their experience in participatory design in the context of risk and natural disasters. This consists of a combination of good practices and professional activity in the field, dating as far back as 1996 with the Lugo di Romagna Master Plan, the first master plan in Italy to which new information and communication technologies (NICT) were applied [20]. It also represents various actors and elements of the participatory design process: From top-down and bottom-up initiatives, to activism and participatory design, through to different levels of inclusiveness (general target, majority vulnerable groups, minority vulnerable groups, etc.) - the type of approach and the role of the very sequence in which all these are activated in time. Last but not least, it highlights the shared responsibility and awareness of redefining the future of both community and territory within a complex system of decisions and actions.

\section{Time and Scale in Participatory Planning}

\subsection{Why Participatory Planning}

The city of Olbia is located by the sea in north-eastern Sardinia. As the capital of the Gallura sub-region, it is the main connection between the island and the peninsula. The city is said to have been settled by the Phoenicians; however, it contains earlier ruins from the Nuragic and Pre-Nuragic periods. The city started to develop in the late 19th century after the unification of Italy, when, along with the modernization of the port, came the arrival of the railway transport. This development has been gradual: From 5000 inhabitants living on 11 hectares in the late 19th century to 15,000 inhabitants on 
43 hectares in the late 1950s. In the 1970s, when Costa Smeralda became one of the highly thought-after Mediterranean holiday resorts, the urbanization of the area exploded. In less than two decades, the population doubled, and the area of developed land grew six times, expanding to approximately 290 hectares. By the beginning of the 21st century, Olbia was a city of 50,000 inhabitants, occupying 750 hectares, second only to Sassari in terms of extension within the island.

When cyclone Cleopatra hit Sardinia on 18 November 2013, carrying six months' average precipitation in as little as $90 \mathrm{~min}$, the tragic consequences of a lack of engagement, awareness, and responsibility toward the built environment became suddenly evident with 16 deaths, many of which could have been avoided, as well as thousands of casualties and damages that further weakened an already-struggling economy. When the cyclone hit, $40 \%$ of the island, including $20 \%$ of the high-risk areas, was not covered by emergency plans, even though the local authorities had been obliged by law to provide them. Their indolence may be explained, yet not absolved, by the fact that Sardinia, in comparison to other Italian regions, is one of the safest. Nevertheless, amongst all the main natural hazards that can commonly happen in Italy-earthquakes, avalanches, landslides, and wildfires-the one that the Sardinian authorities should have most of all taken into consideration was flooding.

Cleopatra caused over 1500 casualties and nine deaths in Olbia, leaving 1500 people homeless and a further 8000 suffering from significant property damage [21]. The estimated social cost of this disaster was 700 million EUR; 90 million EUR were spent on mitigation and 300,000 EUR on direct ordinary maintenance [22].

Along with the sin of omission on the political scale, both national and regional, came unpreparedness at the local level (c.f. Table A2a). Building permissions had been issued not only without a plan or at least a development strategy, but also in areas that were known to be at risk, and this resulted in a vast yet particularly at-risk built environment used and inhabited by a very vulnerable population of tourists and newcomers. An inevitable lack—or erosion-of awareness about the territory aligned with a particular version of the NIMBY syndrome, typical in cases of mass-tourism-oriented development, which can be summarized as: "Do your landscape protection or flood risk management plans elsewhere, because I want to build a house in my back yard," even if the given back yard will be flooded (sooner rather than later). At the end, as the example of Olbia revealed, no one had been educated in how to live and build in the shadow of risk, or how to behave to survive and help others survive. People could not care less about plans and procedures before the cyclone hit and, when it did, no one knew what to do.

More than highlighting a total lack of legal and planning tools, the case of Olbia demonstrates their inefficiency. While the hydrological and hydrogeological risk assessment plan (Piano stralcio per l'assetto idrogeologico; PAI) [23] revealed itself to be simply inadequate, the river management plan (Piano Fasce Fluviali) [24] has never been carried out. A general plan was lacking, along with tools for both implementation and control (c.f. Table A2). Olbia is a representative example of the consequences of a non-participatory model, presented in Figure 2.

From the top down, there were sins, omissions, errors, and oversights, green lights for land speculation, along with the erosion of the local identity and awareness, which resulted in the vulnerability of the urban system (composed of people, structures, infrastructures, and environment). In turn, this made a dramatic, unexpected event even more dreadful in its consequences. Subsequently, the lack of participation and/or activism after the event resulted in the lack of any feedback, including for a simple disagreement. 


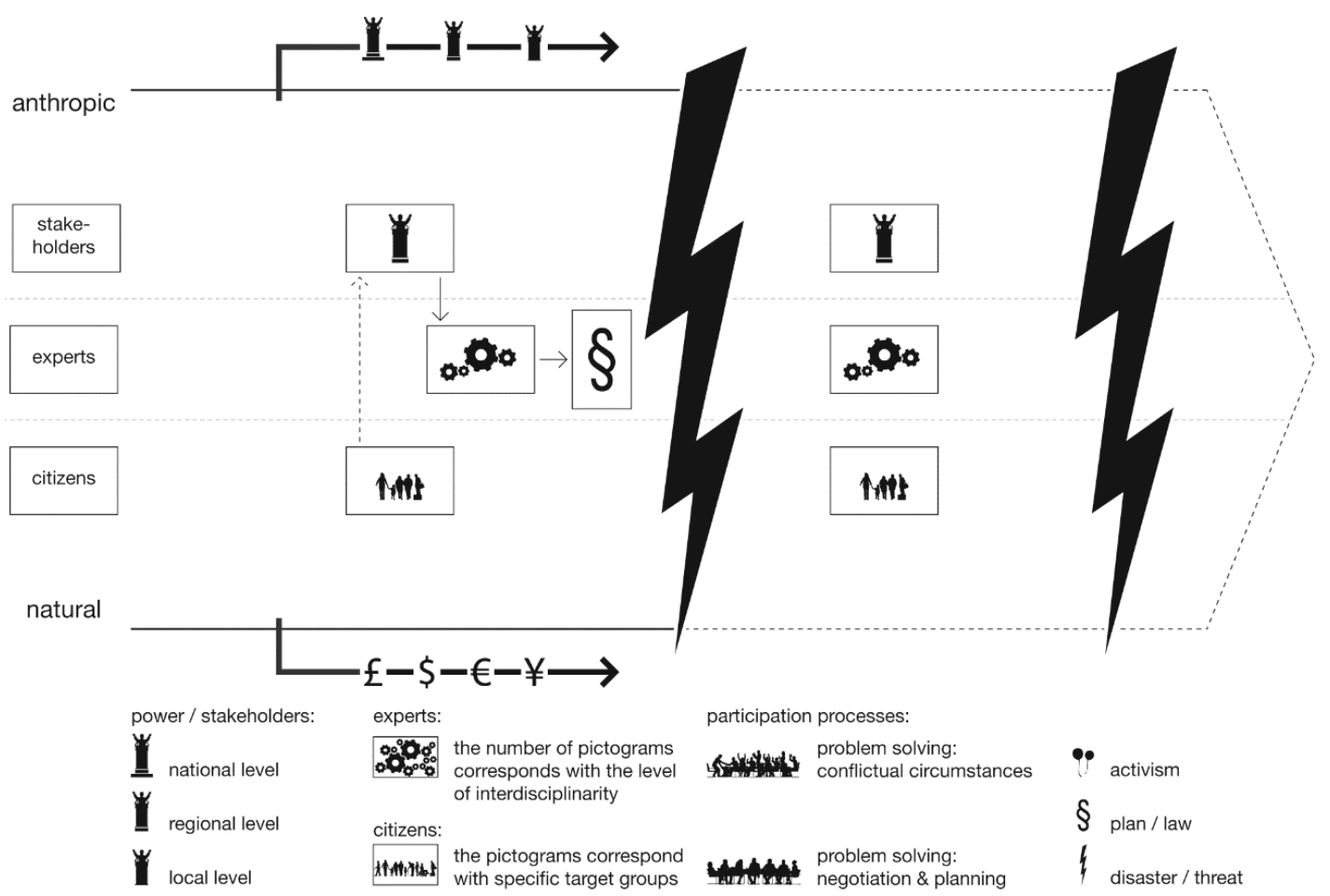

Figure 2. Non-participatory model: Olbia. Top-down initiatives and stimuli (legal, logistic, financial, etc.) are replaced with top-down implementation; no bottom-up initiatives and/or activism resonate or activate changes. The relation is exclusively hierarchical to the extent of refusing or undermining the value of the plans and strategies provided by the experts/planners/designers. In case of emergency, applying this model leads to severe damages and numerous casualties.

As an ounce of prevention is worth a pound of cure, the costs of prevention and mitigation are significantly minor compared to the costs of reconstruction. Furthermore, the individual cost of a house that is built properly in the right place is not necessarily higher than that of one built negligently and improperly in a place that is inconvenient, or, in particular, one exposed to risk. However, the political cost of preventing people from building their houses wherever they want-for example, through the introduction of more restrictive plans-often seems too high for the local stakeholders. Reconstruction and compensation are, instead, subsidized with mysterious "public" money. In the case of Olbia, politicians and stakeholders who had been putting local plans on hold for years were the first to claim indemnity, but the last to admit the consequences of their omissions.

In Olbia, things are staying as they were: The system remains vulnerable and the erosion of the relationship between the people and their environment keeps progressively worsening. There is no community whatsoever, only a crowd of random people hoping that the next flood will leave their back yards untouched.

Instead of being rebuilt as it was, the city of Olbia should change. Its future development should focus on re-establishing its citizens' awareness of environmental risk and educating their behavior, as well as on modifying the infrastructural and settlement policies of the region. Such a challenge is unlikely to be achieved without proper participatory processes: Elements of a smart city policy, changing potential construction sites into green-blue belts, controlled densification of the already-built environment in order to prevent further expansion, reduction or, in some areas, even elimination of individual car traffic, etc. If imposed top-down, these policies will meet the only response a crowd can give: The one of "NO" or "NOT IN MY BACK YARD".

We can only speculate on what the situation in Olbia would have been if participatory processes had been launched before this dramatic event. With much probability, the local community would have at least had a chance to build its own resilience, if not to change the way the city was governed 
and the way it was developing. What is certain, however, is that the lack of participatory planning even after what happened tilts the balance towards future catastrophes. Of all disasters, flooding is the one from which learning is the easiest. Precipitation as rapid and heavy as that of the 18 November 2013 has never been seen before in Olbia, but in the city, as it was in the 1920s or even 1950s, the flooding caused by the cyclone Cleopatra would not have touched a single house $[9,25]$.

\subsection{Participatory Planning After a Disaster}

From a practical point of view, an earthquake, unlike flooding, is always an enigma. It cannot be observed on a regular basis, as it is not a regular event. Regardless of all the sophisticated tools available, all that can be done as far as earthquakes are concerned is to measure them once they strike. Earthquakes cannot be forecast, if not with the shortest possible notice. Some procedures may-and must - be introduced in advance and infrastructures adjusted, but the precise location, time, and scale, both of the event and of the reaction to it, remain unknown. Thus, post-earthquake reconstruction strategies are not planned a priori in Italy. However, given the fact that according to the 2014 report, in the last 50 years, Italy has spent over 120 billion EUR on post-earthquake reconstruction [26-28], a lesson from the pattern that emerges from these processes should be considered worth learning, especially as far as participation is concerned.

Among the seven biggest post-earthquake reconstruction processes that have been launched in Italy in the last 50 years, only two have been accomplished so far. It took ten years to rebuild Friuli and seven years to rebuild Umbria-Marche at the cost of, respectively, 18.5 and 13.5 billion EUR. It is expected that the reconstruction of Emilia-Romagna after the 2012 earthquake will be completed soon. These three processes-as well as the events that caused them-have something in common. The affected population was counted in the hundreds of thousands, but not millions; the number of homeless was one of the higher, but not the highest, and so was the strength on the Richter magnitude scale. What is the most striking point, however, is that these are the only three cases involving participation and community planning in the post-earthquake reconstruction phase (c.f. Table A1). The 1968 Belice earthquake, measuring 6.1 Mw, killed 352 people, injured 576, left 57,000 homeless, and affected a population of over one million. Over the years, the Italian government has spent 9 billion EUR on reconstruction, which has yet to be completed. The 1980 Irpinia earthquake, measuring $6.9 \mathrm{Mw}$, killed 2914 people, injured nearly 9000, left over 280,000 people homeless, and affected a population of six million. So far, the Italian government has spent 52 billion EUR on its reconstruction, and this too has yet to be completed. The $6.3 \mathrm{Mw} 2009$ earthquake in the Abruzzo region that destroyed the city of L'Aquila killed 309 people, injured approximately 1500, and left 67,500 homeless. It directly affected a population of 145,000 , but indirectly affected a population of 1.3 million, as the city it destroyed was the capital of the region. A series of shocks that struck Central Italy in the winter of 2016/2017 destroying, amongst others, Norcia and Amatrice, killed 332 people, injured 392, and left 17,000 people homeless [26-28]. In all these cases (c.f. Table A1), participation was kept off the table.

The first reconstruction that involved participation was after the 1976 Friuli earthquake. Relocation of the homeless, one of the most burning issues in such cases, was a participatory process and, thus, given the circumstances, easily conducted. All parties and all participants in public life univocally put common interest above the private one. Even a bishop of the Catholic Church declared that houses and places of work should be restored first, not the churches. Whilst participation was mostly non-structural, it was aligned with activism; both were rooted in a strong local identity. In the case of the reconstruction after the 2012 earthquake in Emilia-Romagna, a structured, formal, and obligatory participation was legislated for in advance and accompanied by various forms of activism. The top-down impact in this case was very strong, but the bottom-up influence was even stronger (c.f. Table A3). The efficiency of this model lay in the fact that, since the very beginning, it involved the local community, seen as such rather than as dealing with a crowd. This point also gave energy to activism, as presented in Figure 3. 


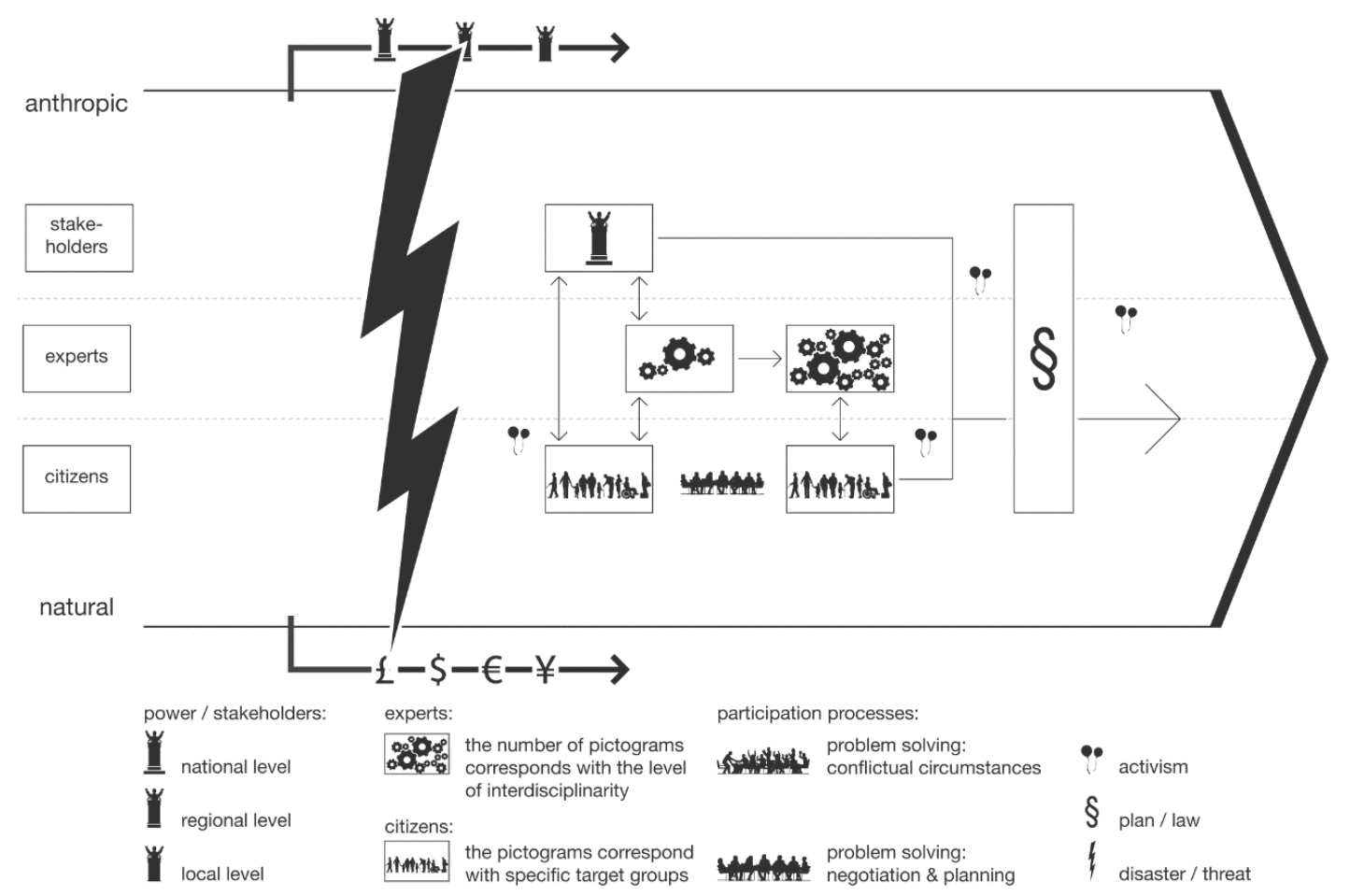

Figure 3. Participation and activism: Emilia-Romagna (Novi di Modena). In this case, strong top-down stimuli, including formal participation, were legislated for. These stimuli were parallel to activism with a prevailing amount of bottom-up activities, which allowed working directly with local communities since the very first phase, immediately after the event. Community planning, along with activism in the subsequent phases, resulted in complex, diversified, and shared feedback, as well as problem-solving strategies that included interests of different users and of the environment. As a result, it allowed a shared top-down/bottom-up implementation.

The situation of L'Aquila was different (c.f. Table A4). The 2009 earthquake found the city of L'Aquila without a plan or a strategy, except for the one regarding protection of the historical city center. The first concern was to secure safety and provide temporary solutions for housing and public administration, but, in comparison to the process adopted in Friuli, relocation in L'Aquila felt more like deportation. The need for an immediate reaction left little time to debate on the mid- and long-term future of the city. Reconstruction of the city center "as it was" was mistaken for physical recovery. Eleven years of this policy have proven it to be without reason, which is no surprise, for, from the outset, it was an approach destined for failure. The phase of embracing change-something that cannot be imposed from the top down-while deciding the strategy for recovery was entirely missing. As presented in Figure 4, citizens were objects rather than subjects in this process, and the future of the entire system is insecure.

In Abruzzo, there was a strong top-down initiative that met with activism. That activism was not structural, and was unable to become so even if it was coordinated and supported by academia. The difference between participation and activism, as the Abruzzo case revealed, is that activism, if not followed by more structural actions, is but a flash in the pan: It is either temporary, quickly burning out, or is limited to shouting an unconstructive "NO". 


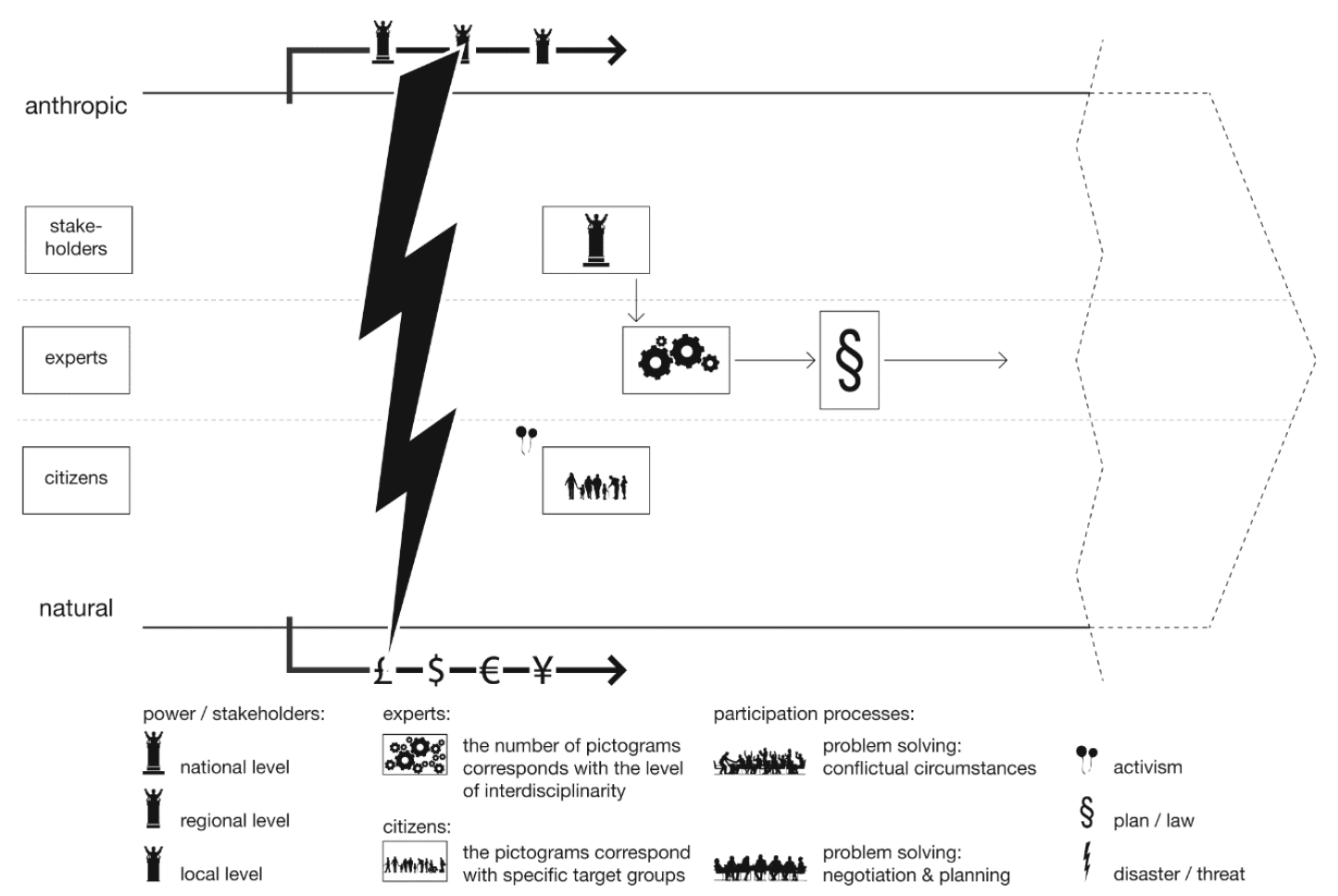

Figure 4. Participation or activism: Abruzzo (L'Aquila). A strong top-down political will crushed local activism. Despite tools including use of social media, it resulted in a lack of structured bottom-up feedback, and subsequently resulted in control and implementation from the top down only.

These two case studies emphasize the role of participation included in the process of a post-earthquake reconstruction. In Emilia-Romagna, the participatory process within the process of reconstruction was well structured and coherent in both the social and environmental aspects, hence its efficiency. In Abruzzo, the central government assumed a role of a deus ex machina, excluding both the local community and groups of interest from the process of reconstruction. As a result, not only was the process incoherent and inefficient, but, to the surprise of the authorities themselves, it was not even coordinated.

\subsection{Participatory Planning During a (Near) Disaster}

Large infrastructural investment inertia is nearly legendary. When legal acts are issued, contracts signed, and political agreements made, it is not the time for second thoughts, however rational. There are some exceptions, however, that break the rule instead of proving it, among which the one of the Livenza River bed and the flood risk management plan for the city of Pordenone are included.

Pordenone is situated in northeastern Italy on the River Livenza. As historical sources, including marks on the walls of the cathedral, reveal, the area of the city suffered regularly from flooding. This kept urbanization within the limits of the slightly more elevated sites, which were reached only during extreme events. However, this natural property of the area was underestimated when the city expanded rapidly in the 20th century. Here, urban development turned a local phenomenon into an over-local crisis.

A plan for the mitigation of hydrogeological risk was issued for the Livenza River in 2006. It was but a desperate endeavor because it attempted to solve the problem caused by infrastructures by providing more infrastructures. It proposed to save and solve the problems of one community, the one that was co-responsible for the situation, i.e., the citizens of Pordenone, at the cost of other, barely involved communities, i.e., the people living along the upper course of the river. In order to diminish — but not to eliminate- the risk of flooding in the area of Pordenone, the plan proposed a set 
of dams that would eventually, but with no certainty, save the city located in the lower course of the river, while other settlements would disappear forever.

Since the Livenza River crosses the provinces of both Venice and Treviso in the Veneto region before reaching Pordenone in the Friuli-Venezia Giulia region, the plan required the issue of a national legal act. This exclusively top-down initiative provoked righteous anger among people living along the upper course of the river, who decided to act against the odds, which are rarely in favor once a legislative and executive machine worth billions of euros is put into motion. The communities concerned, together with their administrators, adopted a different approach: Not the "NO", but the "can we discuss it?", which led to an extended and inclusive participatory process (c.f. Table A5). This efficient and well-structured participation, guided by Monia Guarino and presented in Figure 5, resulted in alternatives that were both cheaper and more effective than the one proposed in the plan and were compatible with the territory in comparison with the conflicting ones proposed in the plan [29]. This was made possible by a profound understanding of the problem and thanks to endless hours of surveys and discussions $[29,30]$.

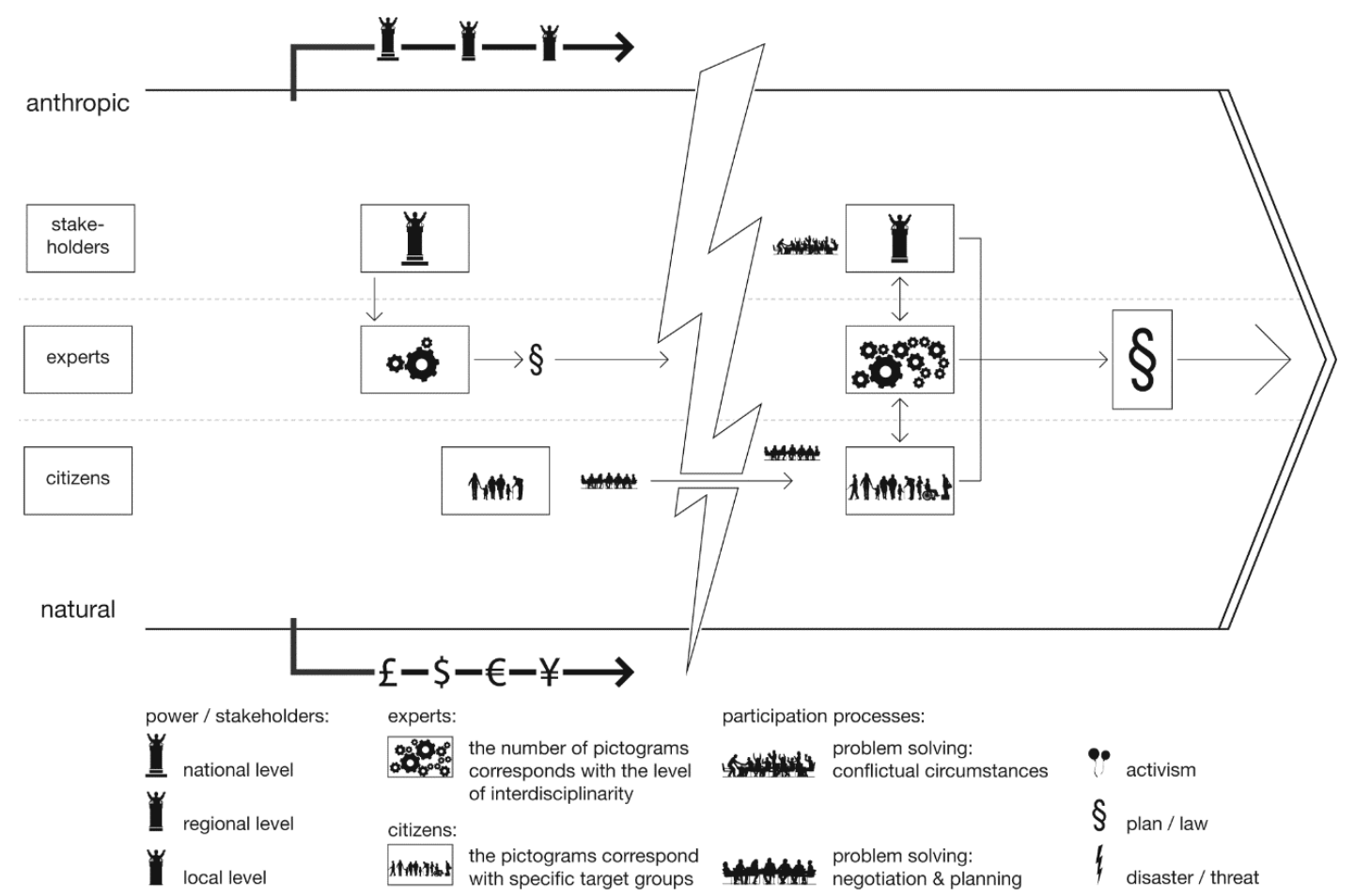

Figure 5. Mitigated top-down participatory model: Pordenone. Top-down initiatives and stimuli (legal, logistic, financial, etc.) were replaced with top-down implementation, resulting in conflict of interest; bottom-up initiatives involved many different groups and changed an already-launched top-down initiative despite having no time for activism or preliminary participation activities. It is an evolution of the standard model: Strong top-down initiative is softened-or turned around-by the competences of the local authorities and stakeholders as much as by the competences and attitudes of the local communities. The output is a new relation between central government, local stakeholders, and the community, which stimulates further inclusive participatory planning initiatives.

According to Innes, "information in communicative practice influences by becoming embedded in understandings, practices, and institutions, rather than by being used as evidence; $(\ldots)$ the process by which the information is produced and agreed on is crucial and must include substantial debate among key players and a social process to develop shared meaning for the information; (... ) many types of information count, other than 'objective' information" [3]. On one hand, what makes the example of Livenza so unique and reassuring is the fact that well-executed participation offered a 
complex and satisfactory, as well as shared, solution. On the other hand, this, by definition, should be a result of any participatory process.

\subsection{Participatory Planning Before a Disaster}

Solving a large-scale problem purely at the large-scale level is a 1970s type of approach, rooted in the realm of statistics as well as in the already-discredited approach of ultimate design. Focusing on immediate or a short-term solutions may eventually save people, but both options will most certainly make them suffer [19,31-34]. Reaching the smallest of scales, like that of a local community or even the individual, both of which are essential for enhancing resilience, requires the effort of participation [19]. Otherwise, all the large scale, top-down initiatives are useless and/or ineffective when it comes to community planning, for they inevitably ignore countless first-person perspectives.

The Kochi region, located on the Shikoku Island in southern Japan, is literally sitting on a ticking bomb called Nankai, or the Nankai Trough, to be exact. The latter is a submarine trough marking the subduction zone between two tectonic plates: The Philippine Sea plate and the Amur plate. The underlying fault, the Nankai megathrust, has been the source of devastating earthquakes called Nankai, Tōnankai, or Tōkai depending on the position of the epicenter along the fault. There have been a dozen of great Nankai megathrust earthquakes (magnitude superior to $8 \mathrm{Mw}$ ) in the last 13 centuries. Each gave rise to a large tsunami that hit the coastal areas soon after the earthquake. The shortest interval lasted 90 years, the longest 200 years, and the average time between earthquakes has been between 100 and 150 years. The last Tōkai (in the northern area of the fault) occurred in 1854 and measured 8.9 Mw. It destroyed 10,000 buildings and killed 2000 people. The last Tonnankai (with the epicenter in the central part) occurred precisely 90 years later. It destroyed 30,000 buildings and killed over 1000 people. Two years later, in 1946, the last Nankai (in the southern part) followed. It destroyed almost 40,000 buildings and killed almost 1000 people. These last two measured $8.4 \mathrm{Mw}$ and $8 \mathrm{Mw}$, respectively, and gave rise to a tsunami that grew to a height of $6 \mathrm{~m} \mathrm{[35].}$

Since the last two earthquakes caused by the Nankai Trough were relatively weak, the imminent one is expected to be stronger, up to $8.9 \mathrm{Mw}$ [35]. Most land areas will experience strong tremors of up to seven degrees, which may continue for as long as $100 \mathrm{~s}$. This means that the next Nankai will be comparable in magnitude to the 2011 Honshiu earthquake, which was responsible for the Fukushima Daiichi nuclear disaster and 40,000 deaths. When it hits, the next Nankai is expected to destroy 153,000 buildings, injure 36,000 people, and kill 42,000 people $[35,36]$.

The second study for Kochi issued in 2004 already presumed that $15 \%$ of the built environment in the prefecture would be destroyed, and $2.5 \%$ of the population would be injured immediately or within $24 \mathrm{~h}$. In such a densely populated area (Kochi is a narrow strip between the sea and the mountains), that percentage is equal to 150,000 buildings and 20,000 people injured, including 10,000 dead. The solution for this can be seen in two diametrically opposed ways: Either participatory planning or totalitarian regime, with only one of the two being acceptable.

In Kochi, citizens and local communities are not objects of imposed procedures, but co-authors of these procedures and subjects of the entire process. The aim of the process is mostly to increase responsibility and enhance resilience, since the scale and time of the event cannot be estimated with precision. Procedures as such are not the goal. The goal is to embrace the risk along with the procedures and make it part of an everyday habit. These habits start within buildings and places that are safe (strong structural points of a building, elevated public spaces, escape routes, etc.) and/or vulnerable (old buildings, depressions, narrow streets, parking lots, etc.), and extend to turning all public spaces into dual ones, which means making them suitable both for everyday life and in case of ultimate emergency. To accustom oneself to the position—and the need-of an evacuation point is one step. To make it a second nature is another $[19,31,32]$. 
The great difficulty of this case lies in both its times and scales: Once the event occurs, the consequences will be immediate (the tsunami will reach the shore after a couple of minutes and will cover the city after a quarter of an hour), but the water will stay for days, weeks, or months, and some of the houses and infrastructures will not be rebuilt for years [36]. Preparing for this requires coordinating on all scales: Large (national and regional budget, chain of command, warning systems, etc.), mid (regional mid- and long-term evacuation centers), small (local evacuation plans and short-term evacuation points), and individual (c.f. Table A6).

The differences between the standard model explained earlier and the one applied in Kochi, presented in Figure 6, are time and scale. The scale of the event, that is, over-regional, and the scale of the pilot processes, which are oriented directly on local communities instead of the broad category of "people", make activist support less relevant, even if still applicable. Community planning in this case considers both the variety of users and the natural environment; it is also simpler and more pragmatic. Since the event is still to come, bottom-up feedback is implemented within subsequent top-down initiatives and support, which remain strong and stimulating.

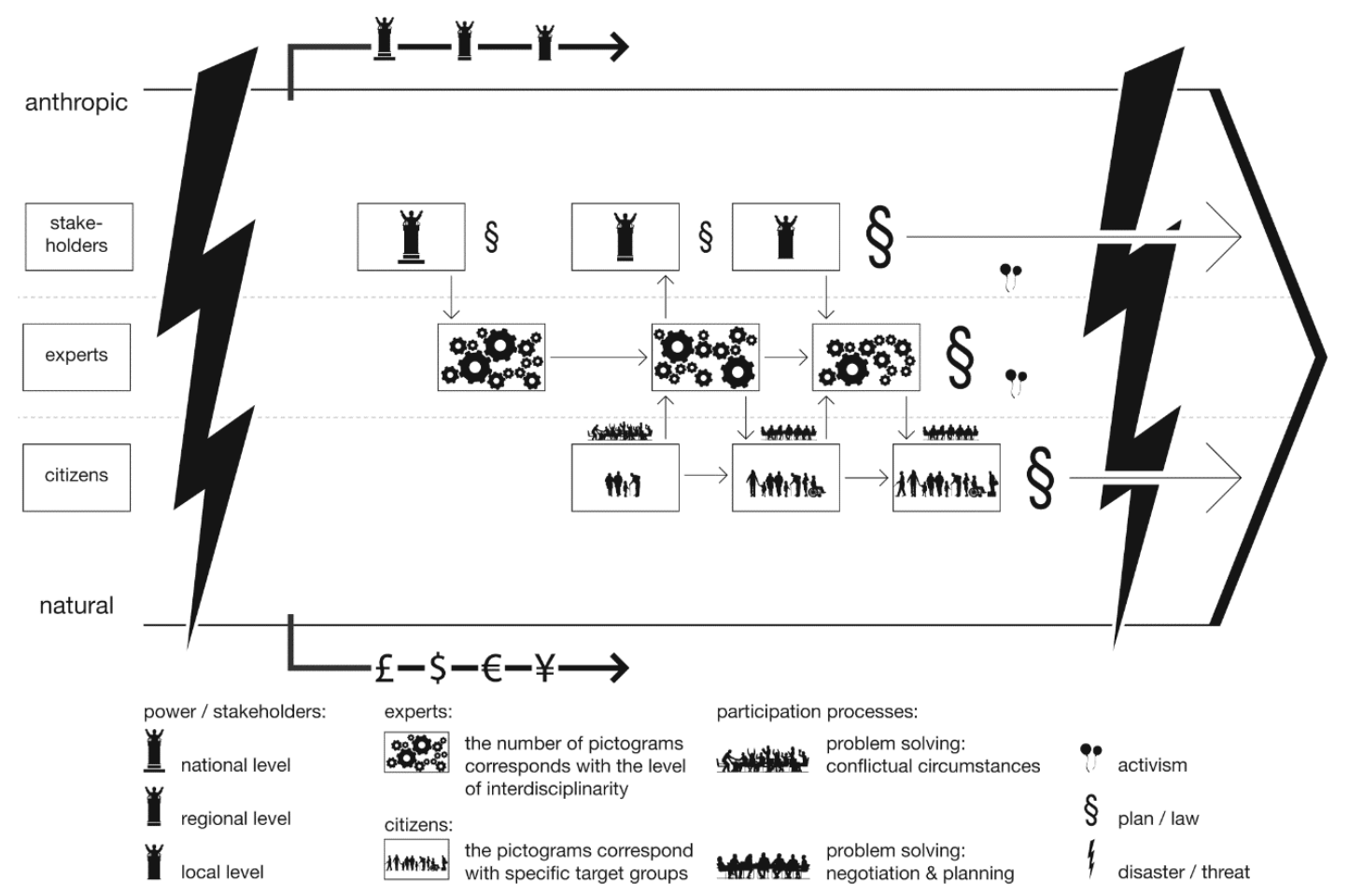

Figure 6. Top-down stimulated participatory model: Kochi. Strong top-down initiatives and stimuli (legal, logistic, financial, etc.) and pilot participatory processes are oriented towards limited but well-defined groups. They leads to implementation followed by a bottom-up feedback, forming subsequent top-down initiatives. Since the scale of the event is too catastrophic for a top-down initiative and makes implementation of any top-down actions too expensive and inefficient in terms of time, the government issues guidelines or strategic plans to be adopted and implemented by local governments. It is up to the latter to activate multi-scale and multi-target participatory processes. Unfortunately, the strength of the bottom-up feedback and the possibility of implementation of needs and propositions resulting from participatory processes depend on social and economic resources of given communities. 


\subsection{Towards a New Framework}

Some vulnerable territories are like cities, and cities are complex but incomplete [37]. Some are complex but overcomplicated, as they are composed of more elements than any design can handle. As stated before and highlighted in the case studies presented, participatory processes in general, and vulnerable areas in particular, are not about giving people what they want or doing what they want done. Non-structural (informal) participation often rises from a "NO", which is the same as activism, and like activism, it may lead nowhere, especially if it is not supported top-down by economics, logistics, or instrumental terms. Structural (formal) participation, if not conducted properly, also results in a lack of feedback, regardless of the initial intentions. Asking people about everything is equally ineffective and produces no more than an over-consulted society. Over-consulting reveals weakness and vulnerability in participation, comparable to applying tools instead of methods. If you ask people what they want, the answer is usually the same: Everything, starting with parking their cars in front of their very doors but living on a safe and quiet street with a nice view from the window-until a crisis comes and changes everything.

According to Klosterman [38], the unrealistic goal of preparing exact predictions in order to prepare a range of scenarios for alternative futures should be abandoned, and the "what if" metaphor popularized by spreadsheets should be adopted instead. We should attempt to build models that are as simple-rather than as complex-as possible, and use visualization to facilitate the exploration of the past, present, and alternative futures-or, as Blečić and Cecchini put it, "a designed, built, and shared future that would be desired enough and imaginable enough to stimulate actions necessary for making it happen" [39]. However, how simple can such a model be?

The greatest dilemma of legal/structured participation is how to involve people in participatory processes. This is definitely not achieved by making participation mandatory. What all the case studies presented above have in common, except for Olbia, is the application of the urban gaming simulation [40-42] as a tool for participatory processes. Just as participation is not about entertainment, the urban gaming simulation is not an urban game. It is a tool adaptable to all goals, be they too big or too small, as it allows the discovery of new scales, new optics, and different points of view. The type of approach that arises from the examples presented above puts some elements of the systems, which seem obvious to the level of being neglected, back into the big picture. These are the constant presence and an intrinsic relation of two key elements: The territory, with its environmental dynamics and threats, which is being framed by policy and the economy, but is bigger than either of them.

Participatory processes considered as a means to educate a resilient community allow citizens to understand or foresee the critical issues and to support parallel top-down initiatives. With risk being mitigated and resilience enhanced, none of the elements of the system are weakened or eliminated, except for those considered negative or critical along the process. Unlike the standard simplified model presented in Figure 1, the model presented in Figure 7, open for interaction, takes into consideration time, scale, and resources. It allows the complexity and diversity of the system, which are too often underestimated when it comes to acting under the pressures of time, casualties, media, or breaking the economy, to be brought into the framework. It represents actions taken in time within a complex and changeable system framed by politics and economy that, by acknowledging the diversity of the system as well as its past, extends the future of policy, economy, and the system itself. 


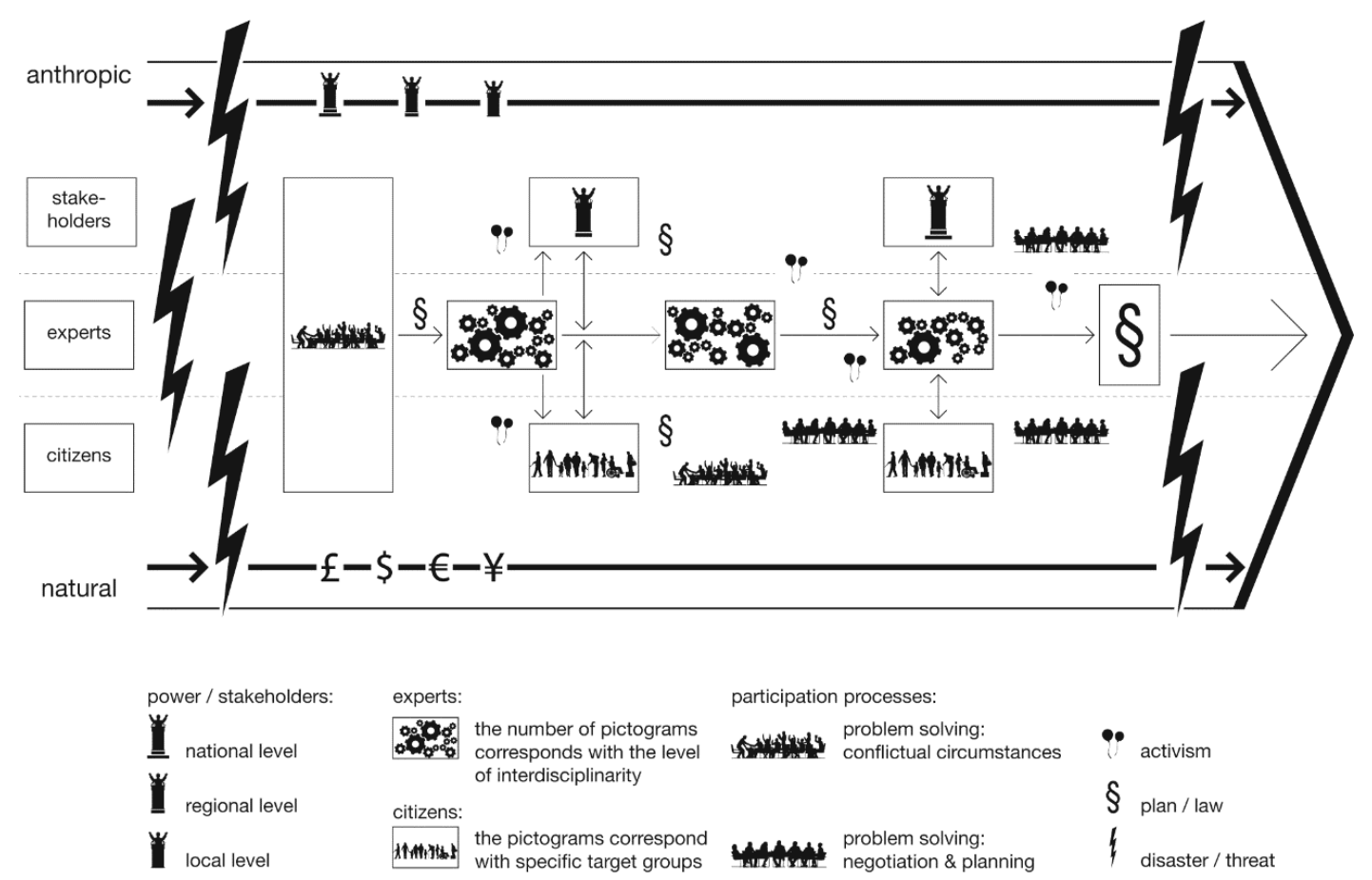

Figure 7. Revised participatory planning framework in the context of risk. Lessons learned from past disasters, regardless of their scale, launch participatory processes involving stakeholders, decision makers, experts, citizens, etc. An interdisciplinary blueprint is subsequently scrutinized by all groups involved. Participatory processes tend to develop towards community planning while the plans are nevertheless provided by interdisciplinary groups of experts. Activism helps to launch the process and keeps the initiative vivid. The final version of the plan, as well as all its blueprints, is oriented towards the future of the system, and they all embrace potential future threats. Policy and economy are considered elements of the system instead of tending to frame it. Hence, their future is no longer separate from the future of the system itself.

\section{Discussion}

Participatory planning requires abandoning the comfortable paradigm of an expert/designer in favor of a more challenging one in which there are no longer clients, but people and duties. In order to succeed, all actors must be well informed, know how to interact, and have the time in which to do it. This time must not be at the expense of other activities, and participation must not be a waste of time. Already according to Healey, "planning processes need to work in ways which interrelate technical and experiential knowledge and reasoning, which can cope with a rich array of values, penetrating all aspects of the activity, and which involve active collaboration between experts and officials in governance agencies and all those with a claim for attention arising from experience of co-existence in shared places" [2]. As in the case studies chosen and presented above, those shared places, extending to shared territory, are the key to participatory processes oriented towards natural risk management and mitigation. Awareness, responsibility, and resilience cannot be enhanced if the territory is excluded. Toffler's change [43] cannot be embraced without embracing the territory.

In the standard participatory framework presented in Figure 1, the system composed of natural and anthropic elements is framed (or intended to be framed) in a temporary political and economic strategy. Actions take place within the system, in the political and economic context. The actors are: Stakeholders and decision-makers (local, regional, or central administration), experts (interdisciplinary or not), and citizens (considered in a more or less inclusive way). The reason of action being taken is a past disaster or a future threat. According to this framework, the stakeholders determine a problem and ask a group of experts-usually interdisciplinary-to provide a solution. The solution is supposed 
to be worked through with vulnerable minority groups participating, but often, this phase is limited to consulting general undefined groups. The results of the more or less participatory process supported by activism are analyzed by a group of experts—usually non-interdisciplinary-who provide a plan implemented by the stakeholders. Participation is used in this model as a tool for training and implementation, but not education. The plan has greater potential than the one provided without any top-down training and bottom-up feedback, but the system remains vulnerable.

In order to turn the standard model into a truly ideal one, it is necessary to take the territory into consideration, and not just the participants or the process itself. If participation were a double helix, top-down and bottom-up would be its parallels, connected through the territory, as they hardly ever intersect in time. In the revised participatory framework presented in Figure 7, the system is considered a result of past processes with a lesson drawn from its past. It is composed of natural and anthropic elements, but, unlike in the reference framework, politics and economy operate within the system. Participatory processes are launched before drafting a plan, which allows the exchange of knowledge between the actors as well as enhancement of the awareness and resilience of the community. Educated citizens co-operate with experts to provide a shared solution supported by both top-down stimuli and bottom-up activism. Once defined, the solution is subsequently scrutinized and tested through participatory processes, again supported by activism. The general aims of these actions are the integrity and resilience of the entire system, and hence-a future.

Participation requires information and communication, but these must be neither redundant nor manipulative. Participation is efficient when it turns people into a community, and when this transformation occurs in the preliminary phase (or when the preliminary phase is already community-oriented). Activism must be followed or supported by more formal participation, otherwise it is useless, and its results are second to no results at all. As Olshansky and Johnson emphasize while presenting their approach to post-Katrina reconstruction in New Orleans, without carefully conducted participation planning, documents present traumatized communities with the magnitude of their loss and the unwelcome reality of more change [44].

The nearer the scale of the process is to the individual, the more efficient the participation is. It is a perspective to be obtained even if the action that the participation is subjected to is on a territorial or global scale. The field in which to act in this matter is the proximity of the city and inhabited environment that becomes more distant. Every interdisciplinary tool—be it walkscape, soundscape, place-making, or any other fashionable slogan - is worth considering in this effort.

Today, making as well as consuming the city is increasingly conditioned by the city's resilience and the resilience of its territory. Such a process entails putting together a myriad number of points of view, needs, interests, and requirements, not to mention common sense. Although this is easy to say, things get complicated in the phase of empowerment. Participation, if conducted properly, can make a decisive contribution to the appropriation or re-appropriation of space by the individuals who actually dwell in it. Where top-down decisions are always political (and consequently fragile), as proven by the recent COVID-19 pandemic, participation reinforces democracy and ensures its durability. The locking-down of nearly half of the planet made even more evident the strength of social relations in contrast with the brittleness and vulnerability of our built environments. The fact that, when talking about social distancing, we are actually referring to physical distancing shows how the concept of social relations is deeply rooted in physical space. So it does not necessarily mean that the very concept of participatory planning must now be redefined, and the approach toward participation completely altered. A lesson that we can learn from this unprecedented experience-the very first global crisis in which people were virtually connected-is the importance of education, awareness, and responsibility, of understanding and embracing our place and role within the complex system. Is this not what participatory planning always wanted to be about?

Author Contributions: Conceptualization, P.R.; methodology, P.R. and A.P.; writing-original draft preparation, A.P.; writing-review and editing, P.R. and A.P.; visualization, P.R. and A.P.; supervision, P.R. All authors have read and agreed to the published version of the manuscript. 
Funding: This research received no external funding.

Conflicts of Interest: The authors declare no conflict of interest.

\section{Appendix A}

Table A1. The most destructive earthquakes in Italy in the last 50 years: (a) Affected population. Compilation of the official data of: Istituto Nazionale di Statistica (ISTAT), Istituto Nazionale Geofisica Vulcanologia (INGV), Dipartimento Protezione Civile (DCP), Centro Studi CNI, Regione Emilia-Romagna, Commissario delegato per la ricostruzione Presidente della Regione Abruzzo [26]. (b) Scale, reconstruction costs, participatory processes (PP), participatory design (PD), and community design (CD) applications; current state of completion [26-28].

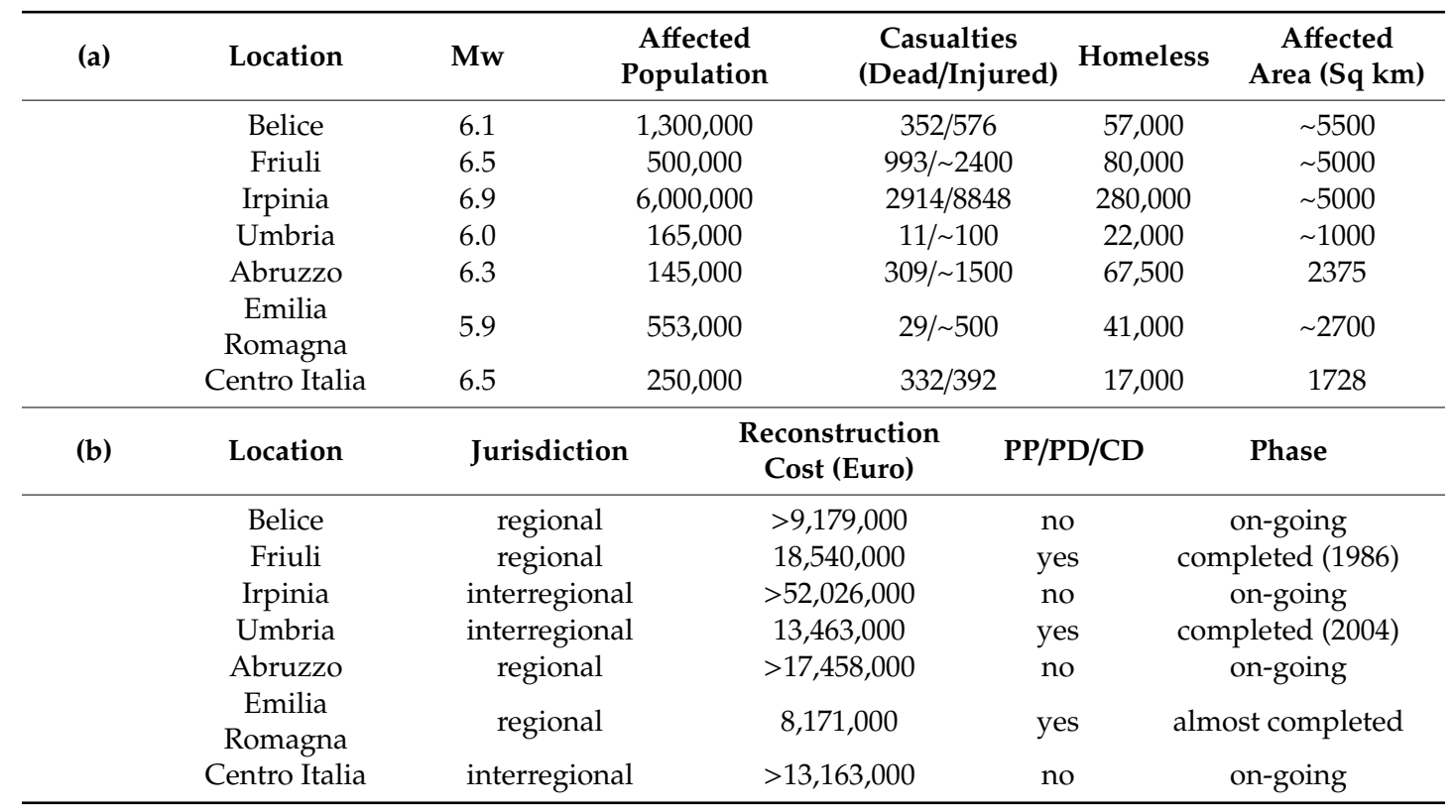


Table A2. The city of Olbia and the Cleopatra cyclone: (a) Scale of the event and countermeasures provided; (b) Timeline of the event in relation to the countermeasures provided; (c) Approaches towards territory in planning, disaster mitigation, and reconstruction strategies; (d) Approaches towards population in planning, disaster mitigation, and reconstruction strategies. The size of a dot corresponds with the strength (big: strong; small: weak), the intensity corresponds with the impact (black: actual/real; gray: potential); n/a corresponds with not applicable.

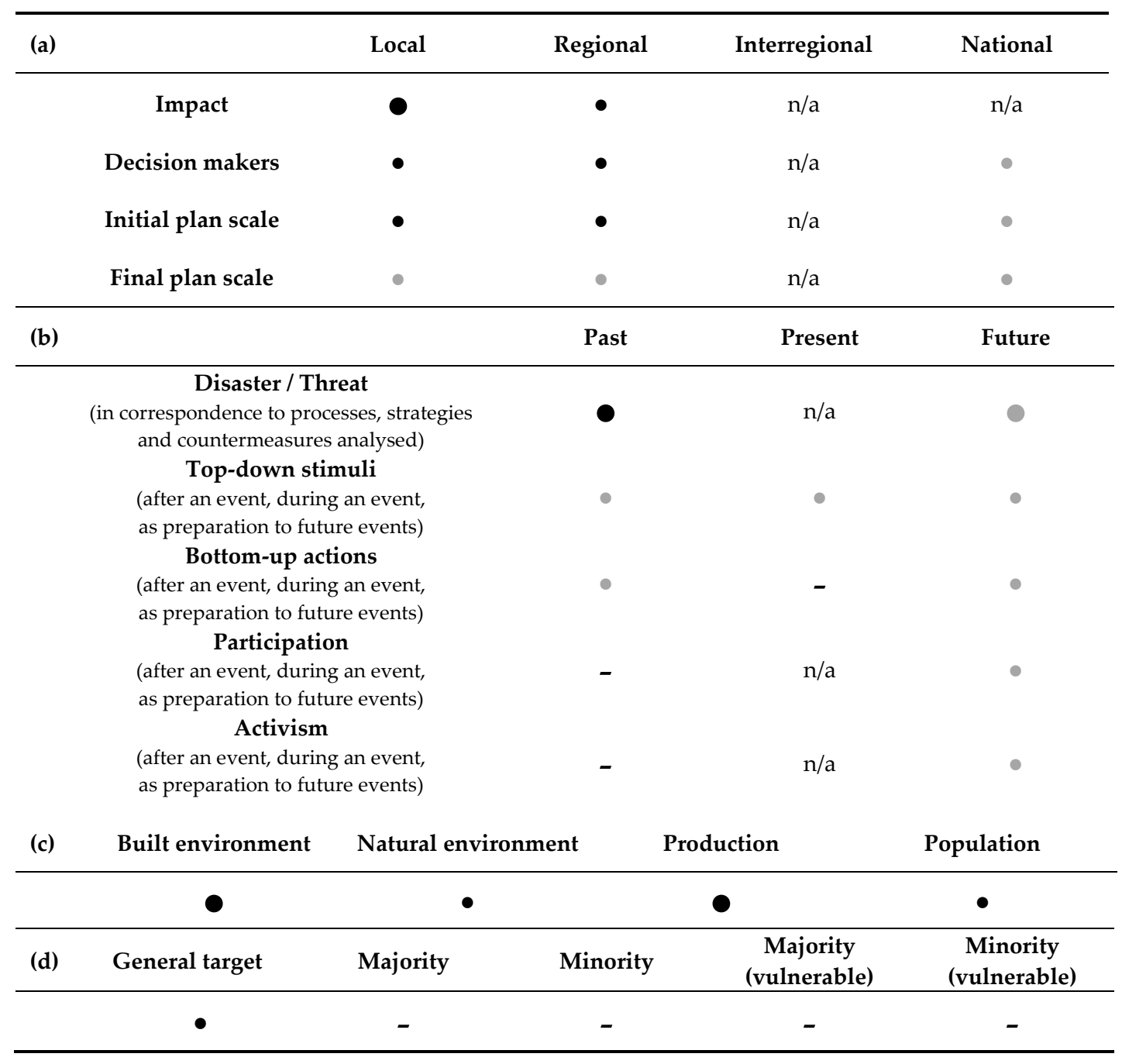


Table A3. The city of Novi di Modena and the 2012 Emilia Romagna earthquake: (a) Scale of the event and countermeasures provided; (b) Timeline of the event in relation to the countermeasures provided; (c) Approaches towards territory in planning, disaster mitigation, and reconstruction strategies; (d) Approaches towards population in planning, disaster mitigation, and reconstruction strategies. The size of a dot corresponds with the strength (big: strong; small: weak), the intensity corresponds with the impact (black: actual/real; gray: potential); n/a corresponds with not applicable.

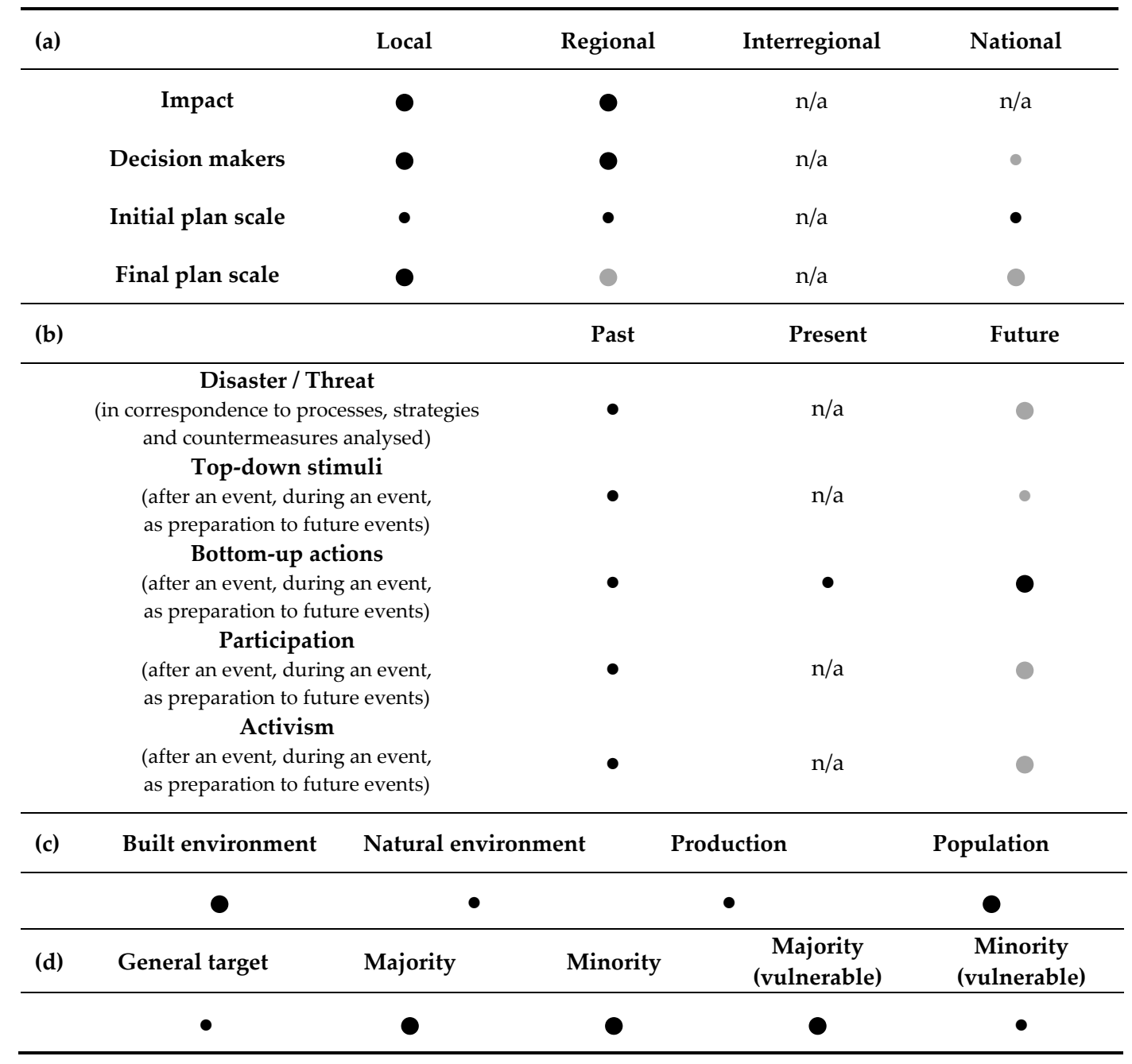


Table A4. The city of L'Aquila and the 2009 Abruzzo earthquake: (a) Scale of the event and countermeasures provided; (b) Timeline of the event in relation to the countermeasures provided; (c) Approaches towards territory in planning, disaster mitigation, and reconstruction strategies; (d) Approaches towards population in planning, disaster mitigation, and reconstruction strategies. The size of a dot corresponds with the strength (big: strong; small: weak), the intensity corresponds with the impact (black: actual/real; gray: potential); n/a corresponds with not applicable.

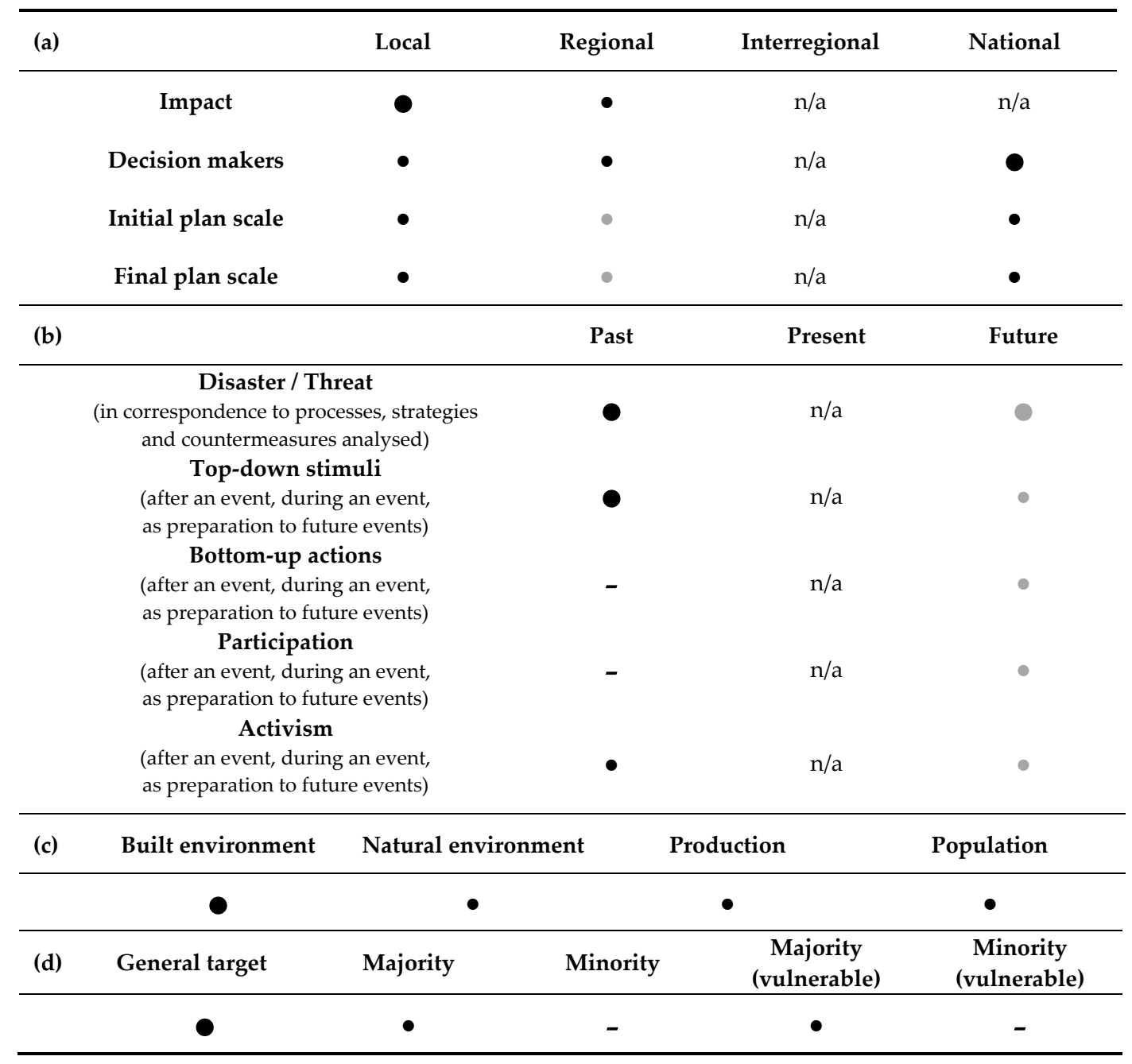


Table A5. The Livenza River regulatory plan: (a) Scale of the event and countermeasures provided; (b) Timeline of the event in relation to the countermeasures provided; (c) Approaches towards territory in planning, disaster mitigation, and reconstruction strategies; (d) Approaches towards population in planning, disaster mitigation, and reconstruction strategies. The size of a dot corresponds with the strength (big: strong; small: weak), the intensity corresponds with the impact (black: actual/real; gray: potential); n/a corresponds with not applicable.

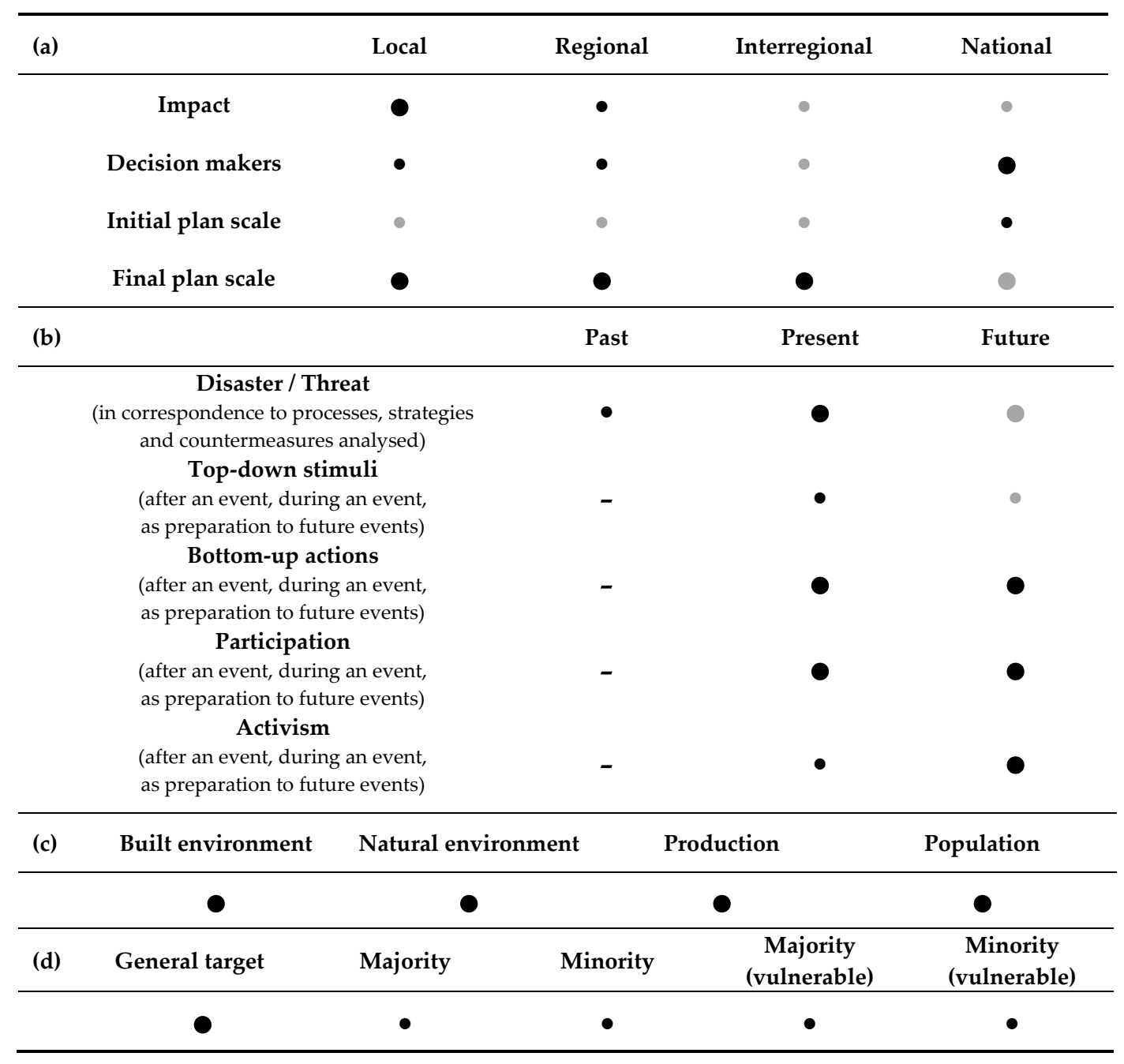


Table A6. Kochi Prefecture preparing for the next Nankai earthquake and tsunami: (a) Scale of the event and countermeasures provided; (b) Timeline of the event in relation to the countermeasures provided; (c) Approaches towards territory in planning, disaster mitigation, and reconstruction strategies; (d) Approaches towards population in planning, disaster mitigation, and reconstruction strategies. The size of a dot corresponds with the strength (big: strong; small: weak), the intensity corresponds with the impact (black: actual/real; gray: potential); n/a corresponds with not applicable.

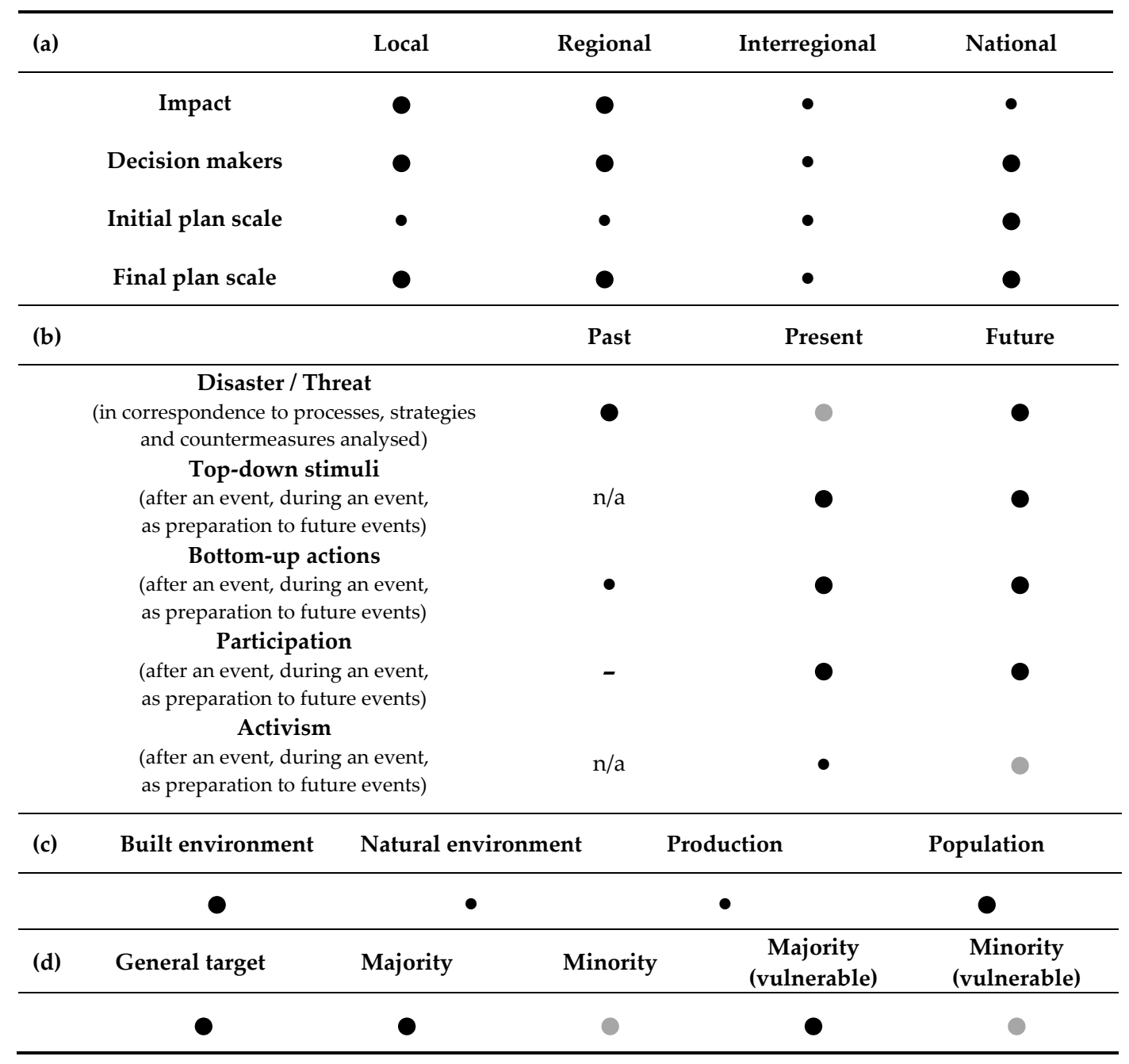

\section{References}

1. Amstein, S.R. A ladder of citizen participation. J. Am. Plan. Assoc. 1969, 35, 216-224. [CrossRef]

2. Healey, P. Collaborative Planning; UBC Press: Vanvouver, BC, Canada, 1997.

3. Innes, J.E. Information in Communicative Planning. J. Am. Plan. Assoc. 1998, 64, 53-63. [CrossRef]

4. Luck, R. Participatory design in architectural practice: Changing practices in future making in uncertain times. Des. Stud. 2018, 59, 139-157. [CrossRef]

5. Meerow, S.; Newell, J.P.; Stults, M. Defining Urban Resilience: A review. Landsc. Urban. Plan. 2016, 147, 38-49. [CrossRef]

6. Godschalk, D.R. Urban Hazard Mitigation: Creating Resilient Cities. Nat. Hazards Rev. 2003, 4, $136-143$. [CrossRef]

7. Klein, R.J.T.; Nicholls, R.J.; Thomalla, F. Resilience to Natural Hazards: How useful is this concept? Environ. Hazards 2003, 5, 35-45. [CrossRef]

8. Walker, W.E.; Haasnoot, M.; Kwakkel, J.H. Adapt or Perish: A Review of Planning Approaches for Adaptation Under Deep Uncertainty. Sustainability 2013, 5, 955-979. [CrossRef] 
9. Rizzi, P.; Porębska, A. Resilient cities. In Future of the Cities-Cities of the Future; Gyurkovich, J., Kantarek, A.A., Gyurkovich, M., Wójcik, A., Eds.; Wydawnictwo PK: Kraków, Poland, 2014; Volume 8, pp. 115-128.

10. Porębska, A.; Rizzi, P. Urban Acupuncture: Dual Spaces as a Strategy for Urban Resilience. In Nano, Bio, Green and Space: Technologies for a Sustainable Future, Proceedings of the SGEM International Multidisciplinary Scientific Geoconference, Vienna, Austria, 27-29 November 2017; STEF92 Technology Ltd.: Sofia, Bulgaria, 2017; Volume 17, pp. 827-834. ISBN 9786197408294. [CrossRef]

11. Sanoff, H. Democratic Design; VDM Verlag Dr. Müller: Berlin, Germany, 2010.

12. Sanoff, H. Editorial. Des. Stud. 1988, 9, 2-3. [CrossRef]

13. Sanoff, H. Community Participation Methods in Design and Planning; John Wiley \& Sons Inc.: New York, NY, USA, 2000; ISBN 978-0-471-35545-8.

14. Sanoff, H. Editorial. Des. Stud. 2007, 28, 213-215. [CrossRef]

15. Sanoff, H. Multiple views of participatory design. Int. J. Archit. Res. 2008, 2, 57-69. [CrossRef]

16. Smith, R.C.; Bossen, C.; Kanstrup, A.M. Participatory design in an era of participation. CoDesign 2017, 13, 65-69. [CrossRef]

17. Smith, R.C.; Iversen, O.S. Participatory design for sustainable social change. Des. Stud. 2018, 59, 9-36. [CrossRef]

18. Guarino, M.; Mashiko, T.; Franz, G.; Satoh, S. Collaborative Planning for Post-Disaster Reconstruction in Italy: Focus on Community Participation in the Town of Novi di Modena. In Proceedings of the 18th International Planning History Society Conference, Yokohama, Japan, 9 July 2018.

19. Porębska, A.; Rizzi, P.; Otsuki, S.; Masahiro, S. Walkability and Resilience: A Qualitative Approach to Design for Risk Reduction. Sustainability 2019, 11, 2878. [CrossRef]

20. Rizzi, P. Using Gaming Simulation on the Web As Participation Tool-Urban Planning: Lugo Case. In Simulation and Gaming for Sustainable Development, Proceedings of the 27 ISAGA Conference, Jurmala, Latvia, 16-19 July 1996; VIDE Environmental Publisher: Riga, Latvia, 1997; ISBN 9984-500-21-7.

21. Mareddu, S. Analisi Demografica Dell'area Colpita Dall'alluvione; Ufficio di statistica del Comune di Olbia: Olbia, Italy, 2013.

22. Mareddu, S. Analisi Socio-economica Dell'area Colpita Dall'alluvione; Ufficio di statistica di Comune di Olbia: Olbia, Italy, 2013.

23. Dovera, D.; Mancini, M.; Salis, M. Piano Stralcio per L'assetto Idrogeologico (PAI), Individuazione e Perimetrazione Delle Aree a Rischio Idraulico e Geomorfologico e Delle Relative Misure di Salvaguardia-legge 267 del 3-08-1998-bacino Unico Regionale, Relazione Generale; Regione Autonoma della Sardegna, Assessorato Lavori Pubblici: Cagliari, Italy, 2004.

24. Mancini, M.; Tilocca, G.; Cittadini, M.; Maurichi, R. Il Piano Fasce Fluviali: Attività e Risultati; Regione Autonoma della Sardegna, Comitato Istituzionale Autorità di Bacino: Cagliari, Italy, 2011.

25. Rizzi, P.; Utzeri, S. How to increase the resilience of territory vulnerable to hydrogeological risk: The case of Olbia. In Urbanistica Informazioni, Special Issue, 2018; Istituto Nazionale di Urbanistica (INU): Rome, Italy, 2018; pp. 311-315. ISSN 0392-5005.

26. Rizzi, P.; D'Ascanio, F.; Di Ludovico, L. From fragile to resilient territories: The reconstruction after earthquakes in Central Italy. In Proceedings of the Joint Conference ISOCARP-OAPA-53rd ISOCARP Congress, Portland, OR, USA, 24-27 October 2017; ISBN 978-94-90354-51-0.

27. CNI Report: I Costi Dei Terremoti in Italia; Centro Studi Consiglio Nazionale Ingegneri. c.r. 470: Rome, Italy, 2014.

28. Report of the Senat of the Republic of Italy: Rapporto dell'Ufficio Valutazione Impatto del Senato della Republica Italiana, August 2017; Senat of the Republic of Italy: Rome, Italy, 2017.

29. Laboratorio Livenza: Percorso Partecipativo per Valutare e Condividere. Documento Conclusive/Final Report; ADBVE: Venice, Italy, 2008.

30. Rizzi, P.; Guarino, M. Emerging Hope After Disaster: The Parcobaleno Project. In Neo-Simulation and Gaming Toward Active Learning; Hamada, R., Soranastaporn, S., Kanegae, H., Dumrongrojwatthana, P., Chaisanit, S., Rizzi, P., Dumblekar, V., Eds.; Translational Systems Sciences: Singapore, 2019; pp. $423-431$. ISBN 978-981-13-8038-9. Online ISBN 978-981-13-8039-6. [CrossRef]

31. Japan Women's Network for Disaster Risk Reduction. Japanese Women's Perspective on 3/11. 2013. Available online: http://preventionweb.net (accessed on 15 November 2015).

32. Porębska, A.E. Spaces of Solitude: People and Places in Deadened Cities. Ph.D. Thesis, University of Sassari, Sassari, Italy, 4 March 2016. 
33. EERI-Earthquake Engineering Research Institute. The Great East Japan Earthquake and Tsunami: Social Dimension. Special Report. (In Japanese). Available online: http://www.eqclearinghouse.org/2011-03-11sendai/files/2011/03/Japan-SocSci-Rpt-hirez-rev.pdf (accessed on 1 March 2019).

34. GFDRR World Bank Report. The Great East Japan Earthquake-Learning from Megadisasters: Knowledge Notes; World Bank: Washington, DC, USA, 2012; Available online: https://openknowledge.worldbank.org (accessed on 1 March 2019).

35. Kochi, P.; (International Spring School PREPARe, Susaki, Japan). Section for Countermeasures for Nankai trough earthquake. Personal communication, 2019.

36. Promsaka Na Sakkannakron, S. Spatial Planning for Tsunami Resilience: A case study of Kochi City, Japan. Ph.D. Thesis, University of Sassari, Sassari, Italy, 6 March 2015.

37. Sassen, S. Unsettling formal power systems. In The Routledge Companion to Critical Approaches to Contemporary Architecture; Chattopadhyay, S., White, J., Eds.; Routledge: London, UK, 2019.

38. Klosterman, R.E. Arguments for and against planning. Town Plan. Rev. 1985, 56, 5-20. [CrossRef]

39. Blečić, I.; Cecchini, A. Verso Una Pianificazione Antifragile. Come Pensare al Futuro Senza Prevederlo; Franco Angeli: Milan, Italy, 2016; ISBN 978-8891727756.

40. Rizzi, P.; Vania, A. Community Visioning e le Nuove Tecnologie dell'Informazione e della Comunicazione: Visti, uditi o compresi? Arch. Di Studi Urbani E Reg. 1999, 65, 45-48.

41. Rizzi, P.; Promsaka Na Sakkannakron, S. Conceptualizing the Essential Role of Gaming Simulation as a Risk Communication Technique for Enhancing Urban Resilience Against Natural Disaster. In The Shift from Teaching to Learning: Individual, Collective and Organizational Learning through Gaming Simulation; Kriz, W., Ed.; Bertelsmann: Bielefeld, Germany, 2014; pp. 345-356.

42. Kumar, S. Methods for Community Participation: A Complete Guide for Practitioners; ITDG Publishing: London, UK, 2002; ISBN 978-1853395543.

43. Toffler, A. Future Shock; Random House: New York, NY, USA, 1970; ISBN 0394425863.

44. Olshansky, R.B.; Johnson, L. Clear as Mud: Planning for the Rebuilding of New Orleans; American Planning Association: Washington, DC, USA; Chicago, IL, USA, 2010; ISBN 978-1138373938. 